\section{International Scientific Journal Theoretical \& Applied Science}

p-ISSN: 2308-4944 (print) e-ISSN: 2409-0085 (online)

Year: $2018 \quad$ Issue: $03 \quad$ Volume: 59

Published: $30.03 .2018 \quad$ http://T-Science.org

\section{Sergey Alexandrovich Mishchik}

Associate Professor,

Candidate of Pedagogical Science, Academician of International Academy TAS, Assistant professor Department of Physics, State Maritime University Admiral Ushakov, Russia sergei_mishik@mail.ru

SECTION 21. Pedagogy. Psychology. Innovation in Education

\title{
SYSTEMIC PROBLEMS ALTERNATING CURRENT OF APPLIED PHYSICS MARITIME FLOT OF PEDAGOGOMETRIC ANALYSIS
}

\begin{abstract}
Navy pedagogometric analysis of the formation of mathematical models of learning activities about the nature of achieving the criteria of life, cycling, systemsness and phasing, which form a basic cell of the educational space, as well as using twelve pointed star Ertsgammy relatively presentation ertsgamming principle which determines the foundations pedagogometric through forming substantive methods of hyper-space professional life, psychological and educational activity theory, psycho-pedagogical system analysis and the theory of the formation of mental actions.

Key words: pedagogometric, vital activity, cyclicity, system, phase, star Erzgammy, alternating current, applied physics, marine fleet.

Language: Russian

Citation: Mishchik SA (2018) SYSTEMIC PROBLEMS ALTERNATING CURRENT OF APPLIED PHYSICS MARITIME FLOT OF PEDAGOGOMETRIC ANALYSIS. ISJ Theoretical \& Applied Science, 03 (59): 234-239.
\end{abstract}

Soi: http://s-o-i.org/1.1/TAS-03-59-40 Doi: crossef https://dx.doi.org/10.15863/TAS.2018.03.59.40

УДК 372.851

\section{СИСТЕМНЫЕ ЗАДАЧИ ПЕРЕМЕННОГО ТОКА ПРИКЛАДНОЙ ФИЗИКИ МОРСКОГО ФЛОТА ПЕДАГОГОМЕТРИЧЕСКОГО АНАЛИЗА}

Аннотация: рассмотрены основные принциипы построения системных задач переменного тока прикладной физики морского флота педагогометрического анализа при формировании математических моделей учебной деятельности относительно характера достижения критериев жизнедеятельности, цикличности, системности и этапности, которые образуют базисную ячейку образовательного пространства, а также применение двенадиати конечной звезды Эригаммы относительно представления приниипа эригаммности, который определит основы педагогометрики через формообразование предметными методами гиперпространства профессиональной жизнедеятельности, психологопедагогической теории деятельности, психолого-педагогического системного анализа и теории формирования умственных действий.

Ключевые слова: педагогометрика, жизнедеятельность, ичиклиность, системность, этапность, звезда Эригаммы, переменный ток, прикладная физика, морской флот.

\section{Introduction}

Формирование системных задач переменного тока прикладной физики морского флота педагогометрического анализа связывается с решением проблемы формирования математических моделей учебной деятельности через базисные представления методологии педагогометрического анализа, который отражает особенности структуры и жизнедеятельности, цикличности, системности и этапности. Результатом педагогометрического анализа является формирование базисной ячейки образовательного пространства, которая отражает принцип эрцгаммности относительно структуру двенадцати конечной звезды Эрцгаммы. Полученнная зависимость устанавливает основы педагогометрики через представление предметных методов гиперпространства 
профессиональной

жизнедеятельности, психолого-педагогической теории деятельности, психолого-педагогического системного анализа и теории формирования умственных действий $[1,2,3]$.

Установленные представления направлены на совершенствование базы предметных прикладных профессиональных задач переменного тока прикладной физики морского флота педагогометрического анализа, отражающих целостную профессиональную деятельность на морском флоте. Формирование математических моделей учебнопрофессиональной деятельности связываются с: базисной звездой Эрцгаммы гиперпространства жизнедеятельности (Е1); базисным целостносистемным циклом жизнедеятельности (Е2); базисной звездой Эрцгаммы системного анализа (E3); базисным проявлением двенадцати этапов и форм познавательного гиперпространства жизнедеятельности относительно образовательного процесса (E4) $[4,5,6]$.

Адаптивное проектирование системных задач переменного тока прикладной физики морского флота педагогометрического анализа и заданной базы предметных педагогометрических моделей эрцгаммного анализа образовательных объектов с признаком базисно-нормативной эрцгаммности, отражают их инвариантные структуры. При этом выполняется собственная функция психолого-математического представления профессионально-значимых объектов системных задач переменного тока прикладной физики морского флота педагогометрического анализа через единство признаков смыслообразования учебнопрофессионального действия, его принятия, ориентировочно-исполнительно-контрольных признаков и прогноза совершенствования анализа объектов педагогометрческого содержания $[7,8,9]$.

\section{Materials and Methods}

$\begin{array}{cccr}\text { Системные } & \text { задачи } & \text { переменного } & \text { тока } \\ \text { прикладной } & \text { физики } & \text { морского } & \text { флота }\end{array}$
педагогометрического анализа отражают целостно-системное моделирование основных элементов транспортных объектов. При этом возникает ориентация на единство базисных характеристик предметных и исполнительных условий относительно предмета содержания и способа его реализации через представление базисной ячейки образовательного пространства, которая отражает принцип эрцгаммности адекватного структуре двенадцати конечной звезды Эрцгаммы. Рассматриваются: сопротивление дроссельной катушки в судовом электромагнитном устройстве при сдвиге фаз между напряжением и током; частота переменного тока, активное и индуктивное сопротивления; полное сопротивление судовой дроссельной катушки относительно активного и индуктивного сопротивления; полное сопротивление цепи в судовом электромагнитном устройстве на морском флоте.

В процессе решения системных задач переменного тока прикладной физики морского флота необходимо применять основные положения теории деятельности, системного анализа и теории формирования интеллекта через построение математических моделей учебнопрофессиональной активности отражающей структуру: базисной звездой Эрцгаммы гиперпространства жизнедеятельности (E1); базисного целостно-системного циклом жизнедеятельности $(\mathrm{E} 2)$; базисной звездой Эрцгаммы системного анализа (Е3); базисного проявления двенадцати этапов и форм познавательного гиперпространства жизнедеятельности относительно образовательного процесса (E4).

Системный анализ предполагает выполнение последовательности системных аналитических действий: выделить объект анализа - задачу переменного тока прикладной физики морского флота (ЗПТПФМФ) как систему; установить порождающую среду ЗПТПФМФ; определить уровни анализа ЗПТПФМФ; представить целостные свойства ЗПТПФМФ относительно про-странственных, и временных характеристик и их комбинаций; выделить структуру уровня анализа ЗПТПФМФ; установить структурные элементы уровня анализа ЗПТПФМФ; определить системообразующие связи данного уровня анализа ЗПТПФМФ; представить межуровневые связи анализа ЗПТПФМФ; выделить форму организации ЗПТПФМФ; установить системные свойства и поведение ЗПТПФМФ.

\section{Задача 1}

В судовом электромагнитном устройстве дроссельная катушка длиной $\ell=50 \quad$ см и площадью поперечного сечения $\mathrm{S}=10 \quad \mathrm{~cm}^{2}$ включена в цепь переменного тока частотой $v=50$ Гц. Число витков дроссельной катушки $\mathrm{N}=3000$. Определить сопротивление $\mathrm{R}$ дроссельной катушки в судовом электромагнитном устройстве, если сдвиг фаз между напряжением и током $\varphi=60^{\circ}$.

Ответ: $R=4,1 \mathrm{OM}$.

\section{Задача 2}

В судовом электромагнитном устройстве конструкция дроссельной катушки состоит из $\mathrm{N}$ $=500$ витков медной проволоки, площадь поперечного сечения которой $\mathrm{S}=1 \mathrm{Mм}^{2}$. Длина 
дроссельной катушки $\ell=50 \mathrm{~cm}$, ее диаметр $\mathrm{D}=5$ см. Определить частоту $v$ переменного тока в судовом электромагнитном устройстве, когда полное сопротивление $\mathrm{Z}$ дроссельной катушки будет вдвое больше ее активного сопротивления $\mathrm{R}$.

Ответ: $\gamma=300 \Gamma u$.

\section{Задача 3}

В судовом электромагнитном устройстве два конденсатора с емкостями $\boldsymbol{C}_{\boldsymbol{1}}=0,2 . м \boldsymbol{\Phi} \Phi$ и $\boldsymbol{C}_{2}=0,1$ $\boldsymbol{м \kappa} \boldsymbol{\Phi}$ включены последовательно в цепь переменного тока напряжением $\boldsymbol{U}=220 \boldsymbol{B}$ и частотой $\boldsymbol{v}=\mathbf{5 0} \boldsymbol{\Gamma} \boldsymbol{u}$. Определить силу тока $\boldsymbol{I}$ в цепи судового электромагнитного устройства и падения потенциала $\boldsymbol{U}_{\boldsymbol{1}}$ и $\boldsymbol{U}_{\boldsymbol{2}}$ на первом и втором конденсаторах системы.

Ответ: $I=4,6 m A ; U_{C l}=73,4 B ; U_{C l}=146,6 B$

\section{Задача 4}

В судовом электромагнитном устройстве дроссельная катушка длиной $\ell=25 \mathrm{~cm}$ и радиусом $\boldsymbol{r}=2 \boldsymbol{c м}$ имеет конструкцию из $N=1000$ витков медной проволоки, площадь поперечного сечения которой $\boldsymbol{S}=\mathbf{l} \mathbf{~ м м}^{2}$. Судовая дроссельная катушка включена в цепь переменного тока частотой $v$ =50 Ги. Определить величину части полного сопротивления $\boldsymbol{Z}$ судовой дроссельной катушки относительно активного сопротивления $\boldsymbol{R}$ и индуктивного сопротивления $\boldsymbol{X}_{\boldsymbol{L}}$ судового электромагнитного устройства.

Ответ: $R=74 \%, X_{L}=68 \%$.

\section{Задача 5}

В судовом электромагнитном устройстве

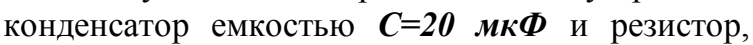
сопротивление которого $\boldsymbol{R}=150 \boldsymbol{O}$, включены последовательно в цепь переменного тока частотой $\boldsymbol{v}=\mathbf{5 0} \boldsymbol{\Gamma} \boldsymbol{u}$. Определить величину части напряжения $\boldsymbol{U}$, приложенного к цепи судового электромагнитного устройства, относительно падения напряжения на конденсаторе $\boldsymbol{U} \boldsymbol{c}$ и на резисторе $\boldsymbol{U}_{\boldsymbol{R}}$.

Ответ: $U c=72,5 \% ; U_{R}=68,5 \%$.

\section{Задача 6}

В судовом электромагнитном устройстве конденсатор и электрическая лампа соединены последовательно и включены в цепь переменного тока напряжением $\boldsymbol{U}=\mathbf{4 4 0} \boldsymbol{B}$ и частотой $\boldsymbol{v}=\mathbf{5 0}$ $\boldsymbol{\Gamma}$. Определить ёмкость $\boldsymbol{C}$ конденсатора судового электромагнитного устройства, чтобы через лампу следовала сила тока $I=0,5 A$ и падение напряжения на индикаторной лампе $U_{\boldsymbol{I}}=110 \mathrm{~B}$.

Ответ: $C=3,74$ мк $\Phi$.
В судовом электромагнитном устройстве дроссельная катушка с активным сопротивлением $\boldsymbol{R}=10 \boldsymbol{O}$ и индуктивностью $\boldsymbol{L}$ включена в цепь переменного тока напряжением $U=127 \quad B \quad$ и частотой $\boldsymbol{v}=\mathbf{5 0}$ Гц. Определить индуктивность $\boldsymbol{L}$ дроссельной катушки, если известно, что дроссельная катушка поглощает мощность $\boldsymbol{P}=\mathbf{4 0 0}$ $\boldsymbol{B m}$ и сдвиг фаз в судовом электромагнитном устройстве между напряжением и током $\boldsymbol{\varphi}=\mathbf{6 0} 0^{\circ}$.

Ответ: $L=55 \mathrm{M} \boldsymbol{H}$.

\section{Задача 8}

В судовом электромагнитном устройстве конденсатор емкостью $\boldsymbol{C}=\boldsymbol{1} \boldsymbol{м \kappa} \boldsymbol{\Phi}$ и резистор с сопротивлением $\boldsymbol{R}=\mathbf{3} \boldsymbol{\kappa} \boldsymbol{\boldsymbol { M }}$ включены в цепь переменного тока частотой $\boldsymbol{v}=\mathbf{5 0} \boldsymbol{\Gamma} \boldsymbol{u}$. Определить полное сопротивление $\boldsymbol{Z}$ цепи судового электромагнитного устройства, если конденсатор и резистор включены: а) последовательно; б) параллельно.

Ответ: а) $Z=4,38 \kappa O m$; 6) $Z=2,18 \kappa O м$.

В судовую электрическую систему переменного тока напряжением $\boldsymbol{U}=\mathbf{2 2 0} \boldsymbol{B}$ и частотой $\boldsymbol{v}=\mathbf{5 0} \boldsymbol{\Gamma} \boldsymbol{u}$ включено судовое электромагнитное устройство, в котором последовательно включены судовой конденсатор ёмкостью $\boldsymbol{C}=35,4$ мк $\boldsymbol{\Phi}$, сопротивление $\boldsymbol{R}=100$ $\boldsymbol{O} \boldsymbol{M}$ и индуктивность $\boldsymbol{L}=\mathbf{0 , 7} \boldsymbol{\Gamma} \boldsymbol{H}$. Определить силу электрического тока $\boldsymbol{I}$ в системе и падения напряжения $\boldsymbol{U} \boldsymbol{c}, \boldsymbol{U}_{\boldsymbol{R}}$ и $\boldsymbol{U}_{\boldsymbol{L}}$ на судовых конденсаторе, сопротивлении и индуктивности судового электромагнитного устройства.

Ответ: $I=1,34 A ; \quad U_{C}=21 \quad B ; \quad U_{R}=134 \quad B$; $U_{L}=295 B$.

\section{Задача 10}

В судовом электромагнитном устройстве индуктивность судового дросселя $\boldsymbol{L}=\mathbf{2 2 , 6} \boldsymbol{м} \boldsymbol{\Gamma} \boldsymbol{\mu}$ сопротивление $\boldsymbol{R}$ включены параллельно в судовую электрическую систему переменного тока частотой $\boldsymbol{v}=\mathbf{5 0} \boldsymbol{\Gamma \boldsymbol { u }}$. Определить сопротивление $\boldsymbol{R}$ судового электромагнитного устройства, если сдвиг фаз между напряжением и током в судовой электрической системе $\boldsymbol{\varphi}=\mathbf{6} 0^{\circ}$.

Ответ: $R=12,3 \mathrm{Om}$.

\section{Задача 11}

В судовом электромагнитном устройстве активное сопротивление $\boldsymbol{R}$ и судовой дроссель индуктивностью $\boldsymbol{L}$ соединены параллельно и включены в судовую электрическую систему переменного тока с напряжением $\boldsymbol{U}=127 \boldsymbol{B}$ и частотой $\boldsymbol{v}=\mathbf{5 0} \boldsymbol{\Gamma \boldsymbol { u }}$. Определить сопротивление $\boldsymbol{R}$ и индуктивность $\boldsymbol{L}$ судового дросселя, если судовое электромагнитное устройство поглощает мощность $\boldsymbol{P = 4 0 4} \boldsymbol{B m}$ и сдвиг фаз между 
напряжением и силой тока в судовой электрической системе $\boldsymbol{\varphi}=\mathbf{6 0 ^ { \circ }}$.

Ответ: $R=40 \mathrm{Om} ; L=74 \mathrm{M} \boldsymbol{H}$.

\section{Conclusion}

Процесс формирования широкопрофильного профессионального мышления ориентируется на организацию всестороннего развития педагогометрической эрцгаммности. Представленные системные задачи переменного тока прикладной физики морского флота педагогометрического анализа выражают основные направления развития и совершенствования базы прикладных предметных педагогометрических моделей образовательных объектов относительно педагогометрического математического моделирования учебного процесса. Это связывается с процессами совершенствования программируемых математических моделей учебной деятельности относительно характера достижения критериев жизнедеятельности, цикличности, системности и этапности $[10,11$, 12].

Педагогометрический анализ определяет глобальную базисную методологию и задаёт метод формирования специалиста широкого профиля - результат реализации целостносистемного учебного процесса. Это позволяет проводить процесс по определению структуры уровня системы задач переменного тока прикладной физики морского флота.

Процесс формирования и определения структуры уровня системы проблем переменного тока прикладной физики морского флота задаётся в общем случае решением двух задач: определением структурных элементов уровня и установлением системообразующих связей между ними. Характер решения этих проблем системы задач переменного тока прикладной физики морского флота устанавливается общим подходом процесса реализации формируемого действия. Системное представление системного действия имеет многомерную нагрузку в реализации данной задачи. Можно выделить различные подходы в решении проблемы определения и формирования структуры уровня системы.

Формально-логическая структура данного действия приводит к реализации определённого графа с установлением узловых точек и связей между ними. В зависимости от различных образовательных целей можно представить линейные, плоские и пространственные системные модели объектов с выделением фундаментальных структурных элементов и соответствующих связей. При этом развитие системы представляется как дифференциация или интеграция структур и отношений между ними.

Задача реализации глобальной цели, подготовка специалиста широкого профиля, предъявляет к действию выделения структуры уровня системы специфические требования. В первую очередь, структура жизнедеятельности имеет циклический характер. Тогда возникающие циклы имеют не просто структурные элементы и связи между ними, а формируются новые предметно-деятельностые образования, которые имеют ядерно-оболочечную структуру. Возникновение связей между ними задаётся предшествующими структурными элементами. Поэтому связи системы задач переменного тока прикладной физики морского флота, имеющие деятельностную структуру, есть форма существования порождающего элемента активного цикла.

Единица системного анализа деятельности специалиста широкого профиля - целостносистемный цикл жизнедеятельности (ЦСЦЖ) устанавливает многомерное пространство широкопрофильной деятельности. Возникающие структурные связи есть отражение структурнофункциональных отношений общего гиперпространства ЦСЦЖ. Системный тип структуры системы задач переменного тока прикладной физики морского флота мгновенно порождает соответствующие связи, которые формируют генетическую форму существования и развития системы. Тогда каждый структурный элемент и соответствующая системообразующая связь представляют целостное единство всего гиперпространства ЦСЦЖ.

Возникающий педагогометрический диполь учебного процесса «учитель-ученик», определяет характер структуры уровня, который зависит от индивидуальных целостно-учебнопрофессиональных характеристик каждого субъекта, мгновенного центра смыслового взаимодействия относительно целеудержания совместной жизнедеятельности, скорости формирования коллективных схем оперативного системного мышления в реализации системы задач переменного тока прикладной физики морского флота. Поэтому в процессе развития многомерных ЦСЦЖ в рамках отдельных гиперпространств, структура анализа каждого уровня также затрагивает и формы существования этих образований, когда каждый этап жизнедеятельности требует поэтапного перехода по мере формирования последующего психофизиологического образа учебнопрофессионального цикла различных форм образовательного процесса, направленного на становление нормативной творческой деятельности. 
Таким образом, действие педагогометрического системного анализа по выделению структуры уровня системы задаётся соответствующим поэтапным смыслом существования и развития педагогометрического диполя ЦСЦЖ. При этом в системе задач переменного тока прикладной физики морского флота синхронно возникают определённые структурные элементы, которые возникают как целостные объекты с заданными пространственными, энергетическими, силовыми, гравитационными, временными, ориентационными и контрольными характеристиками с различными отношениями и сочетаниями. Все предметные условия задают оболочку заданных структур деятельности, которые активизируют процесс развития всего формируемого цикла с постепенным переходом к его относительно-абсолютной целостности.

Выделение структуры уровня системы задач переменного тока прикладной физики морского флота должно учитывать динамический характер поведения и развития ЦСЦЖ педагогометрического диполя. Принцип относительного смещения предметных условий цикла задаёт ориентировочные, исполнительные и контрольные параметры существования и взаимного перехода по мере превращения учебно-профессиональных действий в операции. Одновременно, формируется динамический характер процесса развития системы задач переменного тока прикладной физики морского флота как действия на различных этапах психофизиологического восприятия от ориентировочно-мотивационного до вербальновнутреннего акмеологического содержания. При этом могут возникать колебательные ЦСЦЖ, которые могут стабилизировать систему только за счёт совершенствования связей с внешней средой.
Действие определения структуры уровня системы в целом решает три задачи: определение структуры учебно-профессионального ЦСЦЖ, как инвариантной формы широкопрофильной деятельности на различных этапах её развития в условиях практического и теоретического смыслообразования; формирование инвариантного педагогметрического диполя «учитель-ученик», как условия генетического развития опредмеченной потребности компаундсубъекта интегральной формы деятельности развития в нечётких условиях внешней среды; выделение условий мгновенных точек динамической динамики ЦСЦЖ относительно нормативной творческой деятельности в условиях облачных технологий образовательных пространств широкопрофильной деятельности $[13,14,15]$.

Выделенные процессы образуют базисную ячейку образовательного пространства, а также выражают смысл двенадцати конечной звезды Эрцгаммы относительно представления принципа эрцгаммности. Представленные структуры системы задач переменного тока прикладной физики морского флота устанавливают основы педагогометрики через формообразование предметными методами гиперпространства профессиональной жизнедеятельности, психолого-педагогической теории деятельности, психолого-педагогического системного анализа и теории формирования умственных действий. Установленные критерии жизнедеятельности, цикличности, системности и этапности, которые образуют базисную ячейку образовательного пространства, порождают условия формирования абсолютного инновационного образовательного цикла, отражающего специфическую структуру подготовки широкопрофильно-инновационных специалистов при реализации международных образовательных стандартов алигорамного содержания эревнометрической формы.

\section{References:}

1. Mishchik SA (2014) Pedagogometrika and mathematical modeling educational activity. Materialy Mezhdunarodnoy nauchnoy konferenctsii "Modern mathematics in science" - 30.06.2014. ISJ Theoretical \&Applied Science 6(14): 54-56 Caracas, Venezuela. doi: http://dx.doi.org/10.15863/TAS.2014.06.14.10

2. Mishchik SA (2014) Simulation training activity methods of mathematical logic.
Materialy Mezhdunarodnoy nauchnoy konferenctsii "Eurapean Science and Education" - 30.07.2014. ISJ Theoretical \&Applied Science 6(15): 72-74 Marseille, France. doi: http://dx.doi.org/10.15863/TAS.2014.07.15.13

3. Mishchik SA (2014) Mathematical modeling system integrity-cycle of life activity - first goal pedagogometriki. Materialy 


\begin{tabular}{l|lr|ll|ll} 
& ISRA (India) & $=\mathbf{1 . 3 4 4}$ & SIS (USA) & $=\mathbf{0 . 9 1 2}$ & ICV (Poland) & $=\mathbf{6 . 6 3 0}$ \\
Impact Factor: & ISI (Dubai, UAE) $=\mathbf{0 . 8 2 9}$ & PUHЦ (Russia) $=\mathbf{0 . 2 0 7}$ & PIF (India) & $=\mathbf{1 . 9 4 0}$ \\
& GIF (Australia) & $\mathbf{0 . 5 6 4}$ & ESJI (KZ) & $=4.102$ & IBI (India) & $=\mathbf{4 . 2 6 0}$ \\
& JIF & $=\mathbf{1 . 5 0 0}$ & SJIF (Morocco) & $=\mathbf{2 . 0 3 1}$ & & \\
\hline
\end{tabular}

Mezhdunarodnoy nauchnoy konferenctsii "European Applied Sciences" - 30.08.2014. ISJ Theoretical \&Applied Science 7(16): 77-79. Aix-en-Provence, France. doi: http://dx.doi.org/10.15863/TAS.2014.08.16.13

4. Mishchik SA (2014) Mathematical modeling system integrity-curricular activities - the second problem pedagogometriki. Materialy Mezhdunarodnoy nauchnoy konferenctsii "European Innovation" - 30.09.2014. ISJ Theoretical \&Applied Science 9(17): 126-128 Martigues, France. doi: http://dx.doi.org/10.15863/TAS.2014.09.17.21

5. Mishchik SA (2014) Mathematical modeling holistic-systemic communicative activity - the third task pedagogometriki. Materialy Mezhdunarodnoy nauchnoy konferenctsii "European Scientific Achievements" 30.10.2014. ISJ Theoretical \&Applied Science 10(18): 45-47 Brighton, UK. doi: http://dx.doi.org/10.15863/TAS.2014.10.18.11

6. Mishchik SA (2014) Mathematical modeling integrity - system performance subject - fourth task pedagogometriki. Materialy Mezhdunarodnoy nauchnoy konferenctsii "Eurapean Science and Technology" 30.11.2014. ISJ Theoretical \&Applied Science 11(19): 51-54 Southampton, UK. doi: http://dx.doi.org/10.15863/TAS.2014.11.19.10

7. Mishchik SA (2015) Pedagogometrik - science and academic subject. Materialy Mezhdunarodnoy nauchnoy konferenctsii "European Technology in Science" 28.02.2015. ISJ Theoretical \& Applied Science 02 (22): 103-106 Malmö, Sweden. doi: http://dx.doi.org/10.15863/TAS.2015.02.22.17

8. Zvereva S.V. (1980) Zadachnik po obshhej meteorologii. L.: Gidrometeoizdat 1980 - p.124

9. Tokmazov GV (2014) Matematicheskoe modelirovanie $\mathrm{v}$ uchebno-professional'noy deyatel'nosti. Materialy Mezhdunarodnoy nauchnoy konferentsii «Modern mathematics in science» - 30.06.2014. ISJ Theoretical \&
Applied Science 6(14): 44-46. - Caracas, Venezuela. doi: http://dx.doi.org/10.15863/TAS.2014.06.14.8

10. Tokmazov GV (2014) Mathematical modeling research skills in educational activity methods of probability theory. Materialy Mezhdunarodnoy nauchnoy konferenctsii "Eurapean Science and Technology" 30.11.2014. ISJ Theoretical \&Applied Science 11(20): 66-69 Southampton, United Kingdom. doi: http://dx.doi.org/10.15863/TAS.2014.11.19.13

11. Mishhik N.A. (2016) Pravovy'e osnovy' francuzskoj si-stemy' bor'by' s zagryazneniem morya / Nauchny'e issledovaniya: Informaciya, analiz, prognoz [Tekst]: monografiya / [V.E'.Lebedev, A.A.Sviridenko, V.M.Sokolinskij i dr.]; pod obshhej red. prof. O.I.Kirikova - Kniga 51.- Voronezh-Moskva, 2016.

12. Mishchik NA (2014) The practice of french justice article 228 of the UN convention on the law of the sea. Materialy Mezhdunarodnoy nauchnoy konferenctsii "The European Science and Education"- 30.07.2014. ISJ Theoretical \& Applied Science 07 (15): 93-97. - Marseille, France. doi: http://dx.doi.org/10.15863/TAS.2014.07.15.19

13. Mishhik N.A., Antonenko G.A. (2013) Liniya gorizonta kak gradientny'j perepad V fotograficheskix izmereniyax dlya celej morexodnoj astronomii//E'kspluataciya morskogo transporta. 2013. № 2 (72). Novorossijsk, -p. 23-28.

14. Mishhik N.A. (2000) Optimizaciya metodov morexodnoj astronomii [Tekst]: avto-ref.dis. ... kand. tex. nauk: 05.22.16 / N.A.Mishhik. Novorossijsk, 2000. - 24 p.

15. Mishhik N.A. (2000) Optimizaciya metodov morexodnoj astronomii [Tekst]: dis. ... kand. tex. nauk: 05.22.16 / N.A.Mishhik. Novorossijsk, 2000. - 188 p. 